\title{
Hadean Oceanography: Experimental Constraints on the Development of the Terrestrial Hydrosphere and the Origin of Life on Earth
}

F. J. Ryerson

February 6, 2003

U.S. Department of Energy

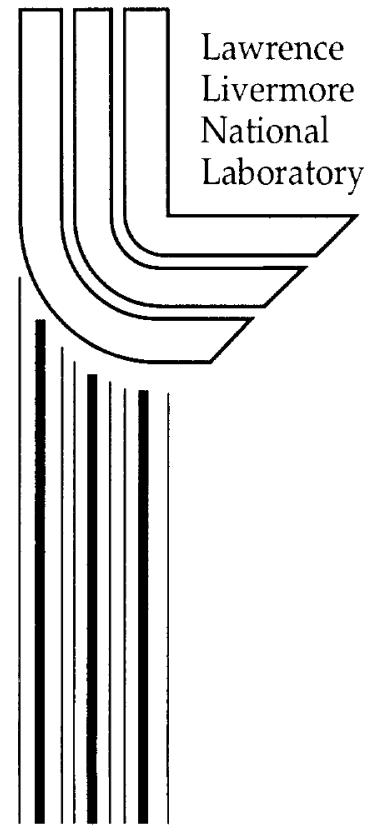




\title{
Hadean Oceanography: Experimental constraints on the development of the terrestrial hydrosphere and the origin of life on earth
}

\author{
F.J. Ryerson \\ Institute of Geophysics and Planetary Physics \\ Lawrence Livermore National Laboratory \\ L-202, 2-6170 \\ ryerson@llnl.gov \\ T. Mark Harrison \\ Dept. of Earth and Space Sciences \\ UCLA \\ And \\ Research School of Earth Sciences \\ Australian National University \\ Canberra, ACT \\ Australia \\ Kevin D. McKeegan \\ Dept. of Earth and Space Sciences \\ UCLA
}

\begin{abstract}
The oxygen isotopic compositions of the world's oldest mineral grains, zircon, have recently been used to infer the compositions of the rocks from which they crystallized. The results appear to require a source that had once experienced isotopic fractionation between clay minerals and liquid water, thereby implying the presence of liquid water at the Earth's surface prior to 4.4 billion years ago, less than 2 million years after accretion. This observation has important implications for the development of the Earth's continental crust. The inferred composition of the zircon source rock is directly dependent upon the oxygen isotopic fractionation between zircon and melt, and zircon and water. These fractionation factors have not been determined experimentally, however, constituting the weak link in this argument. A series of experiments to measure these fractionation factors has been conducted. The experiments consist of finely powdered quartz, a polished single crystal of zircon and isotopically-enriched or isotopically normal water to provide a range of isotopic compositions. The experiments will be run until quartz is in isotopic equilibrium with water. Zircon was expected to partially equilibrate producing an oxygen isotopic diffusion profile perpendicular to the surface. Ion probe spot analysis of quartz and depth profiling of zircon will determine the bulk and surface isotopic compositions of the phases, respectively. The well-known quartzwater isotopic fractionation factors can be used to calculate the oxygen isotopic composition of the fluid, and with the zircon surface composition, the zircon-water fractionation factor. Run at temperatures up to $1000^{\circ} \mathrm{C}$ for as long as 500 hours have not produced diffusion profiles longer than $50 \mathrm{~nm}$. The steep isotopic gradient at the samples surface precludes use of the diffusion profile for estimation on the surface isotopic composition. The short profiles may be the result of surface dissolution, although such dissolution cannot be resolved in SEM images. The sluggish nature of diffusion in zircon may require that fractionation factors be determined by direct hydrothermal synthesis of zircon rather than by mineral-fluid exchange.
\end{abstract}

\section{Introduction}

The geological evolution of the Earth and the development of life on it are inexorably linked. This connection is codified by the Geological Timescale in which the major epochs are delineated by evolutionary changes observed in the fossil record. Less than 30 years ago, the 
oldest macroscopic fossils - 600 million year old - were thought to represent the beginnings of life on Earth, constituting the Cambrian-PreCambrian boundary. The geologic record from this period clearly reveals a planet that is geologically similar to that which we inhabit today. Massive granitic intrusive complexes attest to the presence of stable continental platforms, and the prevalence of water-laid, sedimentary deposits clearly indicates the establishment of a welldeveloped hydrosphere. Hence, one of the major ingredients for life, liquid water, was present and abundant on the planet's surface, but what of the previous 3.9 billion years of Earth history?

Microfossils documented to be as old as 3.5 billion years old push the origins of terrestrial life to a period well before the Cambrian-Precambrian boundary [Schopf, 1993]. More recently the existence of very early terrestrial life has been inferred from carbon isotope ratios bearing a biogenic signature $\left(\delta^{13} \mathrm{C}=-28 \%\right.$ ) from early Archean metasediments from western Greenland [Mojzsis et al., 1996]. The age of these rocks is very close to the oldest rocks yet found on the Earth - the Acasta Gneiss from northern Canada - at 4.0 billion years [Bowring and Housh, 1995].

The period between the end of Earth accretion at $\sim 4.5$ billion years and the production of the oldest terrestrial rocks is known as the Hadean. Some workers extend the Hadean boundary to $3.8 \mathrm{Ga}$ which is the age of the oldest of the large mare plains on the Moon [Ryder et al., 2001] the preservation of these large lava plains indicates they were deposited after the end of the heavy asteroidal bombardment that marks the Lunar Highlands that many have thought would have "frustrated" the development of life on Earth [Maher and Stevenson, 1988].

The surface of the Hadean Earth was clearly much different than today's, and, owing to enhanced sources of energy, so were the major geologic processes. These enhanced sources of energy include latent heat released during accretion and core formation, and radioactive decay half of the heat derived from the decay of ${ }^{235} \mathrm{U}$ was released during the Hadean. In addition, it is widely believed that the Earth collided with a Mars-sized bolide during its initial accretion $(\sim 70 \%$ accreted) which led to wholesale melting of the planet and the formation of a terrestrial magma ocean [Cameron, 2000]. Such a magma ocean would have accelerated planetary differentiation and core formation, and certainly blown off any primordial atmosphere produced by degassing of the early Earth. Given the bulk composition of the Earth and the elevated mantle temperatures during the Hadean, the crust would have been basaltic in composition, rather than the gravitionally bouyant material that constitutes the cores of the present continents. The presence of a lunar magma ocean with similar chemical characteristics to that inferred for the Earth is the reigning paradigm for the differentiation of the lunar interior. 
The Hadean Earth would have been an inhospitable setting for the rise primordial life. Further, the absence of a rock record from this time interval would appear to make documentation of this interval impossible. However, carbonaceous materials supplied by accreting meteorites and sources of chemical energy similar to those that fuel life around modern deep-sea volcanic vents would have been present in abundance. More questionable, however, is the presence of the other ingredient for life - liquid water. Did the surface of the Hadean Earth possess a hydrosphere compatible with the initiation of biologic activity? If so, then the model of a planetary surface characterized by a basaltic crust, devoid of continental material is invalid. Similarly, establishment of a Hadean hydrosphere prior to the cessation of heavy asteroid bombardment may mean that primitive life could have evolved and then been extinguished only to rise again.

\section{“Ambassadors from the Hadean": Evidence for a Hadean hydrosphere.}

In 2001, two papers presented geochronological and oxygen isotopic evidence from detrital zircons found in the metamorphosed sediments from Murchison district of western Australia that suggest the presence of a well-developed Hadean hydrosphere [Mojzsis et al., 2001; Wilde et al., 2001]. The quartzitic gneisses themselves are 3 billion years old [Compston and Pidgeon, 1986; Froude, 1983], but contain zircons that yield $\mathrm{U}-\mathrm{Pb}$ ages as old as 3.9-4.4 billion years - up to 400 million years older than the oldest observed rocks. Zircons $\left(\mathrm{ZrSiO}_{4}\right)$ are both chemically and physically durable and are often incorporated as single detrital grains in sediments,

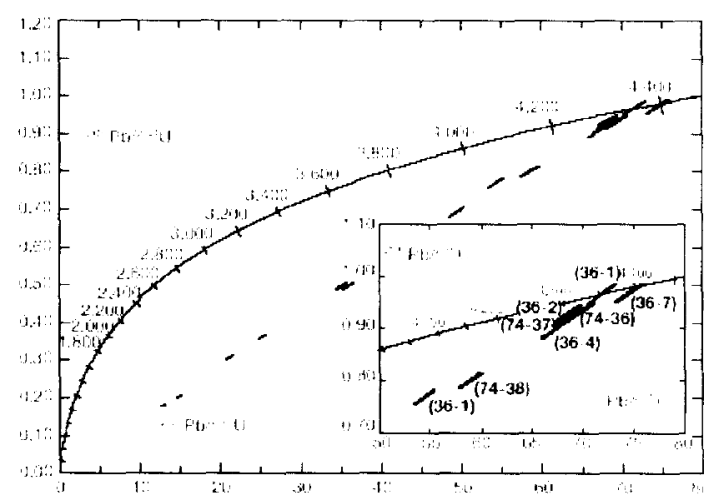

Figure 1. Combined concordia plot for a zircon grain from Jack Hills, western Australia, showing $\mathrm{U} / \mathrm{Pb}$ results obtained using an ion microprobe. The inset shows the most concordant data points. Error boxes are shown at $1 \sigma$. From Wilde et al., snnก even though the original rock in which they were contained, the protolith, may have been completely destroyed by weathering and sedimentary transport, as appears to be the case here. In addition, the affinity of $U$ and $T h$ for zircon, combined with the exclusion of their decay product, $\mathrm{Pb}$, makes zircon the most robust and precise of crustal geochronometers (Figure 1). The $\mathrm{Pb}$ contained in zircon is always highly radiogenic, as opposed to common $\mathrm{Pb}$ incorporated at the time of crystallization. 
The $\delta^{18} \mathrm{O}_{\text {SMOw }}$ values for these zircons, obtained by ion microprobe analysis vary between

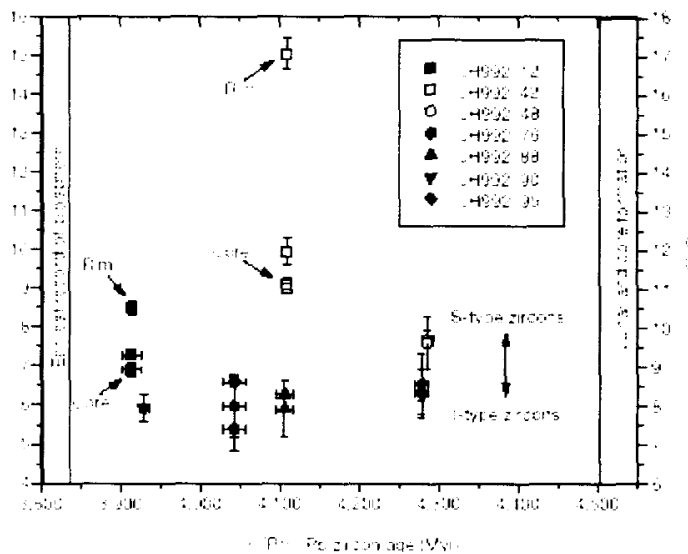

Figure 2. Ion microprobe $\delta^{18} \mathrm{O}$ data for individual zircon spot analyses versus ${ }^{207} \mathrm{~Pb} /{ }^{206} \mathrm{~Pb}$ zircon age. Right vertical axis shows the estimated $\delta^{18} \mathrm{O}$ data for the whole rock from which the zircon crystallized. High $\delta^{18} \mathrm{O}$ values are consistent with the incorporation of source material that has interacted with liquid water.
$5.4 \%$ and $15.0 \%$ (Figure 2). An empirical estimate of the oxygen isotopic fractionation between zircon and granite $(\sim 2 \%)$ was used to estimate the oxygen isotopic composition of the granite magma from which the zircons where derived (Figure 2, right-hand axis). The $\delta^{18}{ }_{\text {smow }}$ of the mantle, estimated to be $5.5 \%$, is unlikely to have changed over time as contemporary midocean ridge and ocean island basalts have identical $\delta^{18} \mathrm{O}$ values of $5.7 \pm 0.2 \%$. In general, granitoids formed by partial melting of metasediments (S-types) are enriched in ${ }^{18} \mathrm{O}$, as opposed to I-type granitoids, which form by melting of igneous rocks derived from arc processes which typically have $\delta^{18} \mathrm{O}$ values below

9\%. The higher $\delta^{18} \mathrm{O}$ values characteristic of granites produced from sedimentary sources is obtained via the low temperature fractionation of oxygen between clay minerals and water. That such high $\delta^{18} \mathrm{O}$ values are found in zircons of this antiquity suggests that liquid water must have been present at the Earth's before 4.4 billion years in order to provide the exchange medium required to produce this observed oxygen isotopic signature. While it is remotely possible that such a heavy oxygen signature could be produced by alteration of hydrous oceanic crust, this mechanism also requires the existence of a planetary scale hydrosphere ${ }^{1}$ prior to 4.4 billion years. No alternate mechanism capable of producing this ${ }^{18} \mathrm{O}$ enrichment is currently known.

\section{Methodology}

The interpretation of the oxygen isotopic composition of zircons depends upon two factors: (1) the value of the oxygen isotopic fractionation factor - the relationship between the composition of the zircon and the melt from which it crystallized and (2) the preservation of their initial oxygen isotopic composition. In the studies described above, the oxygen isotopic fractionation factor was been estimated through analysis of zircons separated from a granite of known isotopic composition. The weakness in this assumption is that the composition of the melt during zircon crystallization is not known. The fractionation of oxygen for zircon-granitic melt

\footnotetext{
${ }^{1}$ While the atmosphere is known to be at least 4.4 billion years old from xenon isotope studies, water in the present oceans would have been present as a $\sim 30$ bar steam atmosphere. Thus, documentation of liquid water at any location at the Earth's surface requires the existence of a global scale hydrosphere.
} 
and zircon-aqueous fluid as a function of temperature has not been measured through direct experiments.

Diffusion of cations and oxygen in zircon has been measured under anhydrous conditions and for oxygen both anhydrous and hydrous conditions [Cherniak and Watson, 2001; Watson and Cherniak, 1997]. The results indicate that, under anhydrous conditions, the oxygen isotopic composition of zircon is likely to be preserved over geologic time. However, hydrous measurements demonstrate an enhancement of oxygen diffusion. Hence, it is possible that fluid interaction could alter the initial isotopic composition of zircon grains. This possibility and its implications for the interpretation of the oxygen isotopic record make it more important that the isotopic fractionation of oxygen between zircon and fluid be determined experimentally. It is under such hydrous conditions that the initial oxygen isotopic composition is most likely to be reset. As such, experimental determination of the isotopic fractionation of oxygen between (1) zircon and aqueous fluid and (2) zircon and melt for a range of relevant crustal temperatures is required.

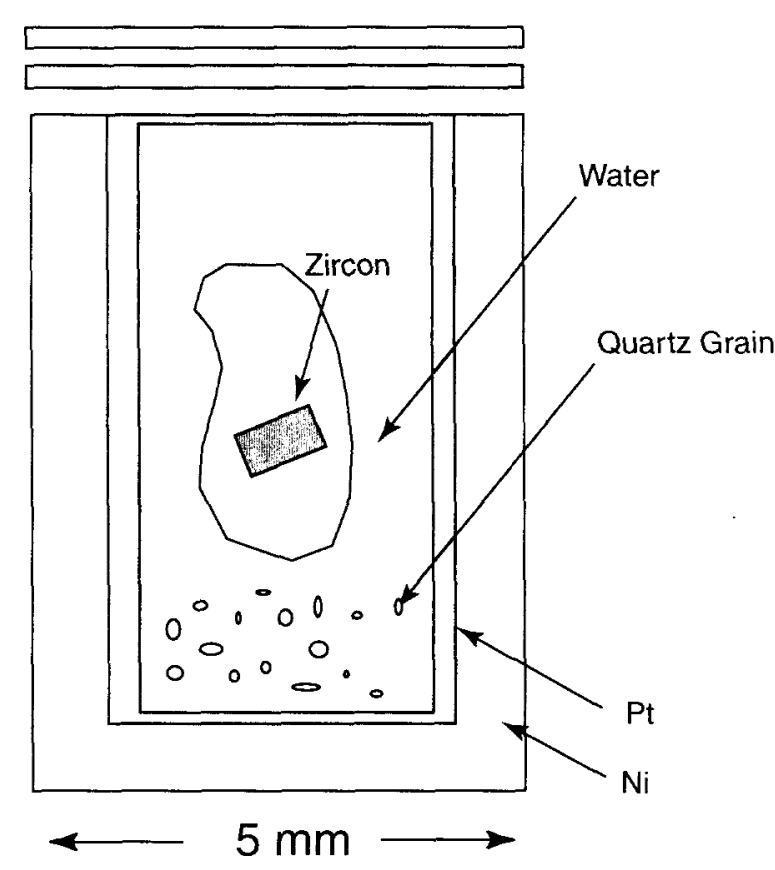

Figure 3. Zircon-fluid experiment. Outer capsule contains the quartz and water, while the inner capsule contains a polished single crystal of zircon.
The kinetics of reactions involving zircon are notoriously sluggish. Obtaining isotopic equilibrium by direct crystallization of zircon from either a melt or aqueous fluid is unlikely. As such, we have devised an experimental method in which zircon is partially equilibrated with a fluid or melt via oxygen diffusion in which the diffusive profile can be used to constrain the equilibrium oxygen isotopic composition. The method is illustrated for zircon-fluid in Figure 3.

To determine the oxygen isotopic fractionation of oxygen between zircon and aqueous fluid, a polished and annealed slab of single crystal zircon will be encapsulated with water and finely

divided quartz $\left(\mathrm{SiO}_{2}\right)$ in a Pt-lined, $\mathrm{Ni}$ capsule suitable for annealing in a piston cylinder apparatus at crustal pressures and temperatures. The zircon slab will be enclosed in an inner, 
perforated Pt capsule that will allow continuous contact with the fluid, but not with the quartz that is enclosed in the main capsule.

During the experiment, both zircon and quartz will attempt to equilibrate with the aqueous fluid. Fractionation of oxygen isotopes between quartz and fluid is well known experimentally, as are the diffusion parameters for oxygen diffusion in quartz under aqueous conditions. The run duration and quartz grain size can therefore be determined such that quartz reaches isotopic equilibrium with the fluid. The fluid composition can be determined by analyzing the quartz grains (with the ion microprobe) and using the accepted quartz-water oxygen isotopic fractionation factors to determine the composition of the fluid. Under these conditions the zircon will only partially equilibrate with the fluid via diffusion. Ion probe depth profiling can then be used to determine the isotopic diffusion profile within the surface of the polished zircon slab. This profile should adhere to the solutions to Fick's Law relevant to a constant surface composition, and having determined the profile at depth, the surface oxygen isotopic composition - that which is in equilibrium with the fluid - can be determined by extrapolation. This method does not require (technically problematic) direct analysis of the fluid which in fact is likely to undergo isotopic fractionation during quenching of the experiment. In our approach, only ion microprobe analysis of solid materials is required. An analogous method can be used to determine zircon-melt fractionation, with the exception that both the quenched melt and zircon can be readily analyzed directly.

While the idea of attacking isotopic fractionation involving refractory solid phases through partial equilibration is innovative, the overall configuration of the experiment using large, fluid-

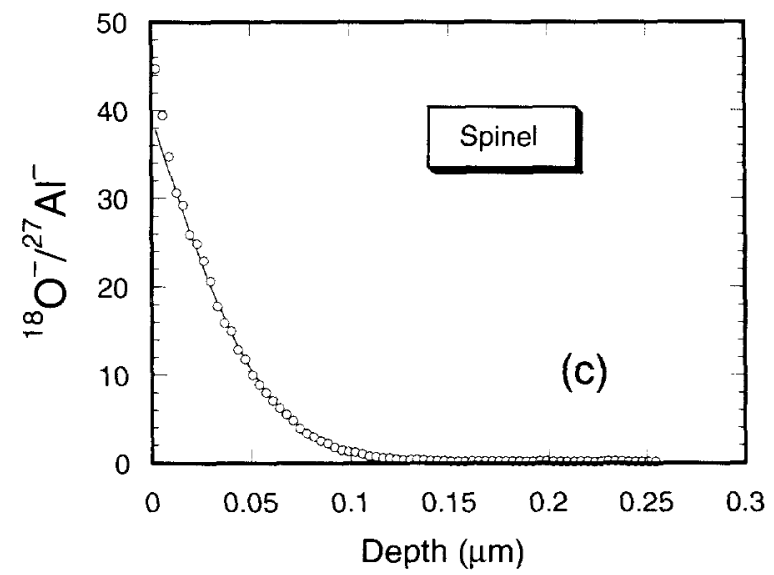

Figure 4, Spinel diffusion profile determined by ion microprobe depth profiling [Ryerson and McKeegan, 1994]. filled, Pt-lined, metal capsules is relatively routine in our lab and has been used previously to investigate mineral-fluid elemental partitioning [Brenan et al., 1994; Brenan et al., 1995a; Brenan et al., 1995b]. Similarly, we have used the ion microprobe to determine oxygen diffusion profiles with great precision and depth resolution [Ryerson and McKeegan, 1994] (Figure 4). Previous diffusion experiments have used ${ }^{18} \mathrm{O}$ as a tracer, but have not quantitatively determined the ${ }^{18} \mathrm{O} /{ }^{16} \mathrm{O}$ ratio along the profile with the precision required for this experiment. Here

we use the Cameca $3 \mathrm{f}$ ion microscope at LLNL using a primary Cs beam that will allow oxygen isotopic analysis to be performed. A similar methodology has been used to determine zoning of 
$\mathrm{Pb}$ isotopes in natural zircon [Harrison, personal communication, 2001]. In that investigation, $\mathrm{Pb}$ was a minor element, while in the proposed work $\mathrm{O}$ is a major element in zircon. As such, we expect no difficulties with the proposed analytical procedures. Experiments for both zircon-fluid and zircon-melt fractionation have been performed in the temperature range $700-1000^{\circ} \mathrm{C}$ at 1 $\mathrm{GPa}$ pressure. Isotopically normal water, and water doped with ${ }^{18} \mathrm{O}$ will be used to vary the isotopic composition. The fractionation factor should not be affected by the variation in bulk isotopic composition, but the variation will allow reproducibility to be verified.

\section{Results}

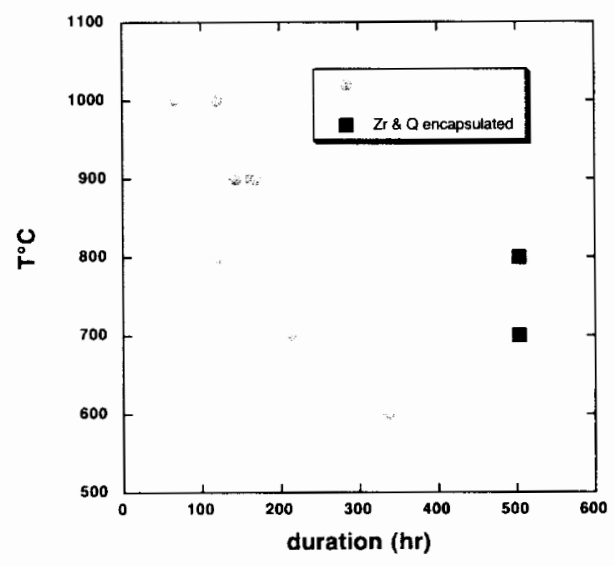

Figure 6. Run conditions used in this investigation
The range of P-T conditions and run times used in this investigation are shown in Figure 5. The experimental method was quite effective in preserving the flat, wellpolished character of the starting zircon grains over the entire P-T-t range (Figure 5). In addition, the quart $\mathrm{Z}$ powder added to the capsule appears to have fully recrystallized during the experiments (Figure 6). The determination of surface oxygen isotopic compositions has been hindered by two factors, however. As demonstrated in the Figure 8, at temperatures above $900^{\circ} \mathrm{C}$, the depth profiles are extremely short, and the steep isotopic gradient near the surface precludes confident extrapolation to the surface with the depth

resolution currently attainable. At temperatures below $900^{\circ} \mathrm{C}$, the surface of the zircon becomes armored with quartz preventing direct contact between the zircon and the fluid. The short isotopic profiles suggests that, in spite of the polished appearance of the post-run crystals, the zircon surface is dissolving in the supercritical aqueous phase, essentially eroding the diffusion gradient away. The quartz armoring of zircon in lower temperature runs is indicative of dissolution of the high surface area crushed quartz with epitaxial recrystallization of quartz on the zircon substrate. Another series of experiments containing both zircon and quartz slabs and zircon powder has been started in the hopes of ameliorating these difficulties. Due to the sluggish nature of diffusion in zircon, it may ultimately be necessary to obtain fractionation factors by synthesis of zircons from reactive precursors rather than through direct mineral-fluid exchange. 


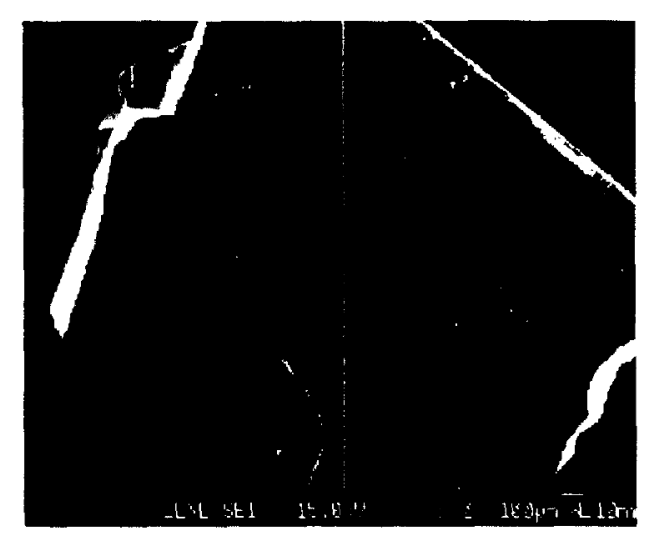

a

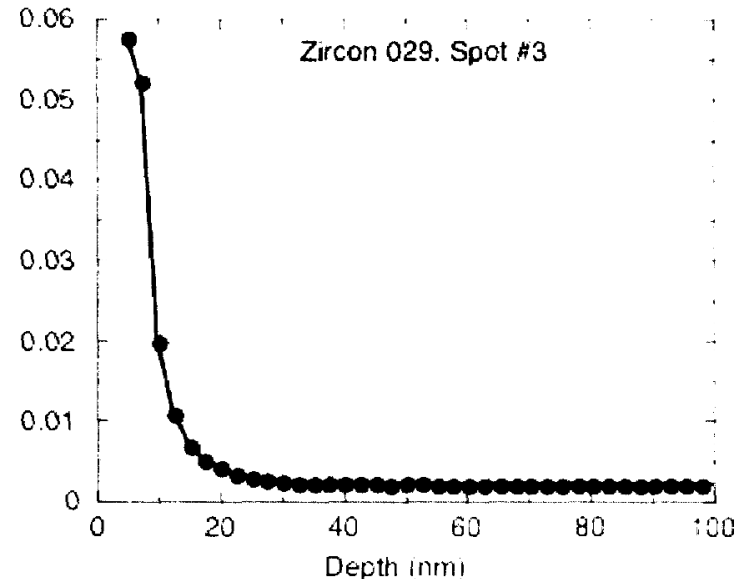

b

Figure 7. a) Zircon grain recovered after 168 hours at $900^{\circ} \mathrm{C}$ and $6 \mathrm{~kb}$ pressure, b) oxygen depth profile on sample in $7 \mathrm{a}$.

\section{References}

Bowring, S.A., and T. Housh, The Earth's early evolution, Science, 269, 1535-1540, 1995.

Brenan, J.M., H.F. Shaw, D.L. Phinney, and F.J. Ryerson, Rutile-Aqueous Fluid Partitioning of $\mathrm{Nb}, \mathrm{Ta}, \mathrm{Hf}, \mathrm{Zr}, \mathrm{U}$ and $\mathrm{Th}$ - Implications For High-Field Strength Element Depletions in Island-Arc Basalts, Earth and Planetary Science Letters, 128 (3-4), 327-339, 1994.

Brenan, J.M., H.F. Shaw, and F.J. Ryerson, Experimental Evidence For the Origin Of Lead Enrichment In Convergent-Margin Magmas, Nature, 378 (6552), 54-56, $1995 \mathrm{a}$.

Brenan, J.M., H.F. Shaw, F.J. Ryerson, and D.L. Phinney, Mineral-Aqueous Fluid Partitioning of Trace-Elements At 900- Degrees-C and 2.0 Gpa - Constraints On the Trace-Element Chemistry of Mantle and Deep-Crustal Fluids, Geochimica Et Cosmochimica Acta, 59 (16), 3331-3350, $1995 \mathrm{~b}$.

Cameron, A.G.W., Higher resolution simulations of the giant impact, in Origin of the Earth and Moon, edited by R.M. Canup, and K. Righter, University of Arizona Press, Tucson, AZ, 2000.

Cherniak, D.J., and E.B. Watson, $\mathrm{Pb}$ diffusion in zircon, Chemical Geology, 172 (1-2), 5-24, 2001. 
Compston, W., and R.T. Pidgeon, Jack Hills, evidence of more very old detrital zircons in Western Australia, Nature, 321, 766-769, 1986.

Froude, D.O., Ion microprobe identification of 4100-4200 Myr old terrestrial zircons, Nature, $304(616-618), 1983$.

Maher, K.A., and D.J. Stevenson, Impact Frustration of the Origin of Life, Nature, 331 (6157), 612-614, 1988.

Mojzsis, S.J., G. Arrhenius, K.D. McKeegan, T.M. Harrison, A.P. Nutman, and C.R.L. Friend, Evidence for life on Earth before 3,800 million years ago, Nature, 384 (6604), 55-59, 1996.

Mojzsis, S.J., T.M. Harrison, and R.T. Pidgeon, Oxygen-isotopic evidence from ancient zircons for liquid water at the Earth's surface 4,300 Myr ago, Nature, 409 (178-181), 2001.

Ryder, G., C. Koeberl, and S.J. Mojzsis, Heavy bombardment of the Earth at 3.85 Ga: The search for petrographic and Geochemical Evidence, in Origin of the Earth and Moon, edited by R.M. Canup, and K. Righter, pp. 475-492, University of Arizona Press, Tucson, AZ, 2001.

Ryerson, F.J., and K.D. McKeegan, Determination Of Oxygen Self-Diffusion In Akermanite, Anorthite, Diopside, and Spinel - Implications For Oxygen Isotopic Anomalies and the Thermal Histories Of Ca-Al-Rich Inclusions, Geochimica Et Cosmochimica Acta, 58 (17), 3713-3734, 1994.

Schopf, J.W., Microfossils in the early Archean Apex Chert: New evidence for the antiquity of life, Science, 260, 640-646, 1993.

Watson, E.B., and D.J. Cherniak, Oxygen diffusion in zircon, Earth and Planetary Science Letters, 148 (3-4), 527-544, 1997.

Wilde, S.A., J.W. Valley, W.H. Peck, and C.M. Graham, Evidence from detrital zircons for the existence of continental crust and oceans on the Earth 4.4 Gyr ago, Nature, 409, 175-178, 2001. 